\title{
ENTREVISTA A LA DRA BEATRIZ BOZA
}

\section{Socia de la firma Ernst \& Young (EY) en Gobernanza y Sostenibilidad Corporativa}

\section{LAURA HUAMÁN PULGAR}

- Profesora de Planeamiento Estratégico y Diseño Organizacional y Procesos

Área Académica de Administración, UPC

\section{ESTUDIOS}

Abogada por la Pontificia Universidad Católica del Perú, Master en Leyes por la Universidad de Yale y graduada del PAD de la Universidad de Piura. Es especialista en gobierno corporativo, ética pública y ética de abogados.

\section{TRAYECTORIA PROFESIONAL}

Profesora en el Programa de Alta Dirección y de Gobierno Corporativo del PAD Escuela de Dirección, Universidad de Piura. Catedrática de Derecho en la Pontificia Universidad Católica del Perú y Universidad del Pacífico en Ética para Abogados. Fue Directora del Banco Central de Reserva del Perú (2006-2012), Jefa del Gabinete de Asesores del Ministro de Economía y Finanzas (2001), Presidente de Indecopi (1995-2000) y PromPerú (1996-2000), así como directora independiente de empresas en los sectores mineros, agroexportador y textil.
Hace más de diez años, se instituyó el gobierno corporativo en las empresas privadas. Si trasladamos esa iniciativa a la actualidad ¿cuáles serían las principales razones para adoptarlo? ¿Qué cambió en el entorno?

Hay empresas en el Perú que tienen prácticas de gobierno corporativo robustas, desde hace mucho tiempo y hay otras empresas que están adoptando esta práctica. Por ejemplo, Buenaventura tiene un comité de auditoría, hace más de 50 años y tiene una mayoría de directores independientes; esas son buenas prácticas; y no de los últimos 10 años, sino incluso de la época de don Alberto Benavides de la Quintana.

¿Qué es lo que ha cambiado este siglo, en el Perú y en el Mundo? Una mayor exigencia sobre lo que ocurre en lo que podríamos llamar la cajita negra de la empresa, el directorio; negra en el sentido que no se conoce hacia afuera que es lo que pasa alrededor de esa mesa y a raíz de, lo que pasó a comienzos de siglo con Enron \& Cía., después con Lima Andrade \& Cía., es que hay mucho más escrutinio en un mundo globalizado sobre lo que ocurre en las compañías y, sobre todo, sobre el proceso de toma de decisiones al más alto nivel.

Hacia afuera lo que hay es mayores exigencias, por parte de los inversionistas institucionales básicamente, en las AFP mucho mayor nivel de exigencia, mayor exigencia 
también a nivel de la banca, mayor exigencia también a nivel del regulador y por parte de los empresarios y gerentes mayor convicción de que el gobierno corporativo lo que ayuda es a aportar competitividad a la empresa. Entonces, son una serie de factores que llevan hoy día a que uno diga, oye ¿Porque no botamos la basura en la calle? porque ya sabemos que no es una manera de ser, que uno debe de tirar la basura en el basurero adecuado y porque vamos adquiriendo nuevas prácticas.

\section{¿Redefiniría el contenido y definición del gobierno corporativo y sus principios para la actualidad? ¿En qué áreas enfatizaría?}

Hay distintas definiciones de que cosa es gobierno corporativo, la OECD ${ }^{1}$ tiene una definición, la IFC ${ }^{2}$ tiene otra, $\mathrm{CAF}^{3}$ y la SMV ${ }^{4}$ también; pero en general de lo que se trata es cómo se hace más predecible y completa la toma de decisiones en los más altos estamentos de la empresa privada. Entonces, si uno lo quiere ver así, el gobierno corporativo debe buscar cinco cosas, por un lado lo que quiere todo accionista, que haya más rentabilidad, para eso debe tener una buena estrategia de negocios: tiene que ser eficiente, toda rentabilidad del mundo sirve de poco, si es que, hay fraudes, si es que no tienes un sistema de gestión de riesgos que garantice el resguardo patrimonial; todo el mejor resguardo patrimonial la mejor estrategia de negocios sirve de poco si es que el inversionista no tiene información; el inversionista sea un inversionista institucional o un miembro de la familia de una empresa familiar, requiere tener información de cómo va el negocio para poder programarse; pero además requiere que le dé un trato igualitario, un trato justo; no que los hermanos que están en la gerencia o los familiares que tienen el control versus los que son minoría, terminen viéndose abusados y todo lo anterior (la rentabilidad, la mejor estrategia, el mejor resguardo patrimonial, la mayor transparencia, el trato igualitario) serviría de poco.

Si la empresa no perdura en el tiempo, si la empresa por ejemplo pierde la licencia social para operar, o si la empresa no tiene una cultura adecuada a los tiempos que le permita garantizar que cumpla con la ley; entonces estas cinco patas como lo podría decir; todo lo que es sostenibilidad, el medio ambiente, la comunidad el respeto de la ley, todos los temas que tienen que ver con gestión de riesgo, todo lo que tiene ver con buen modelo de negocios, todo lo que tiene que ver con transparencia y todo lo que tiene que ver con justicia y los partícipes de la organización ese es gobierno corporativo y es lo que quiere cualquier inversionista.
1. Organización para la Cooperación y Desarrollo Económico

2. Corporación Financiera Internacional

3. Corporación Andina de Fomento

4. Superintendencia de Mercado de Valores

\section{Sobre los valores y la ética que soportan a las organizaciones y sustentan el gobierno corporativo ¿qué mejores prácticas recomendaría? ¿Podría decirse que una revisión de los valores y diálogo sobre la ética empresarial son necesarios ahora?}

Lo que se pide hoy día, es cada vez más valores y más ética a todo nivel de la organización.

Con la bolsa de valores nosotros hace tres años llevamos a cabo una encuesta, a los principales partícipes del mercado de capitales, que son los inversionistas institucionales, los reguladores, la banca, los agentes de la bolsa que incluyen las entidades de research, las calificadoras de riesgo, las cajas de bolsa, los expertos vinculados en un sentido más estrictos de mercados capitales y de esas encuestas más o menos trecientas cincuenta cada uno de los años. En un año tuvimos más de cuatrocientas encuestas, $y$, lo que el mercado peruano grita, es que requiere más trasparencia, más y mejor calidad de información, en segundo lugar, lo que piden es que se garantice el trato igualitario y minoritario, también hablan de directorios más profesionales donde el rol de un director independiente es vital y bueno todo el tema de las relaciones adecuadas con los stakeholders o grupos de interés incluyendo hasta el propio estado.

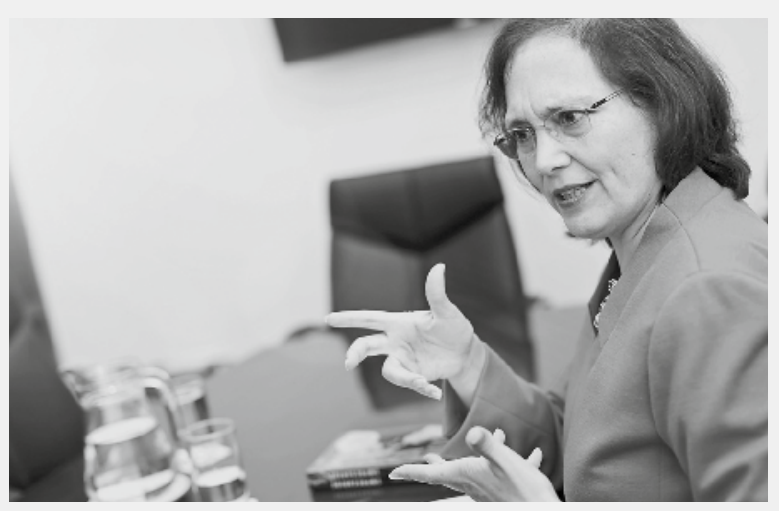

\section{Para quienes aún no adoptan el gobierno corporativo en sus organizaciones, sobre todo en el caso de empresas familiares, ¿cuáles serían sus recomendaciones para hacerlo?}

La empresa familiar tiene por un lado las características típicas de cualquier negocio, como preocuparse de una estrategia y modelo de negocio que sea potente y sostenible y eso es aplicable a cualquier tipo de empresa. Además de eso y quizás dentro de eso, tiene que ver cómo consigue temas de financiamiento para poder seguir creciendo. Además de eso, la empresa familiar lidia, con la familia y las emociones que están vinculadas al negocio. No es lo mismo una empresa en que todas las personas son contratadas porque son las mejores; en una empresa donde hay alguien que es el dueño, que es el hijo, o que es sobrino, se genera una dinámica especial, en la cual los temas por ejemplo, de sucesión, de cómo vas a manejar los conflictos que pueden haber entre cada una de las ramas familiares, de cómo puedes dejar claro cuáles son los requisitos para poder ingresar a la empresa, en que no 
basta llevar el apellido del patriarca sino que le toca además tener el mérito suficiente y ser el mejor. Tener reglas claras consensuadas y queridas por todos los miembros de la familia, es un desafío adicional y ocurre que las empresas que se ordenan, por ejemplo, en procesos de sucesión bien definidos y gestionados, terminan teniendo una visión de largo plazo que las hace más competitivas que las empresas llamémoslas comunes y corrientes.

\section{Con relación a la institucionalidad en el gobierno corporativo, ¿podría profundizar en el tema y proponer algunos indicadores de su adopción? ¿Cuáles serían sus recomendaciones para mejorar nuestras instituciones?}

Al interior de la empresa tenemos tres instancias, la junta general de accionistas, el directorio y la gerencia general, para esas tres instancias, de lo que vemos en ese trabajo que venimos haciendo en la Bolsa de Valores y en las reuniones con los emisores y con los inversionistas y todo lo que vemos, tenemos más de 2500 comentarios escritos, que hemos recibido, claramente hay oportunidades de mejora; oportunidades de mejora en términos de la calidad de información como mencionaba, hay oportunidades de mejora en términos tener de juntas generales bastante más potentes y algunos indicadores para ello, podrían ser por ejemplo, en la junta general se nombra al directorio, y en muchas juntas generales todavía no se anuncian de antemano quienes son los candidatos a ser Director y se envía una pequeña nota biográfica de ellos, para que los accionistas puedan evaluarlo o tienen un reglamento claro, de cómo se va a manejar la junta y distintos temas, eso respecto a la junta general hay oportunidades de mejora, tanto en las empresas cotizadas en bolsa, como en las empresas familiares, no, porque eso te va a permitir que la empresa familiar tener un cierto consenso, que la empresa se está llevando bien, a nivel de los directorios, se demandan directorios más profesionales que puedan haber independientes, en el directorio, los estándares peruanos hablan de un tercio, ya hay estándares en otros países que hablan de porcentajes incluso de más altos, pero la idea es tener independientes en el directorio, lo que ayuda es que no estoy maximizando mi partecita sino me estoy preocupando que esta empresa perdure en el tiempo y la responsabilidad es con la sostenibilidad de la empresa, que pasa por que sea rentable, si no es rentable va a quebrar y bueno para la gerencia general hay temas que tienen que ver con la gestión de riesgo, la calidad de la información, que todas son la responsabilidad también de los directores, de supervisar que eso exista.

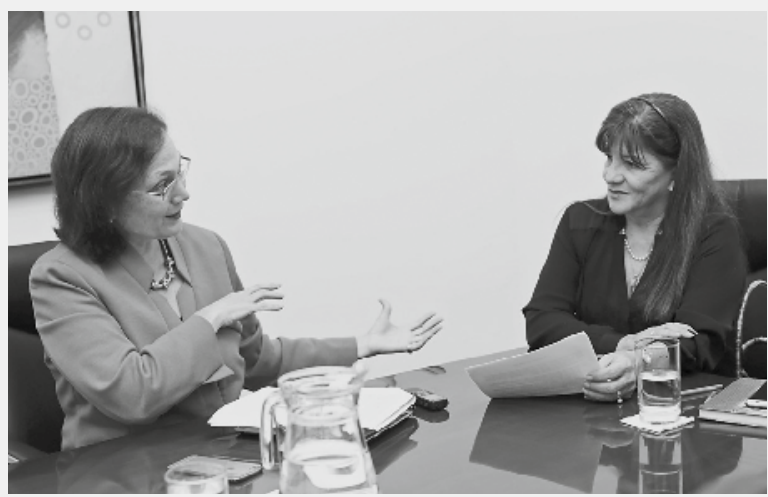

Sobre el desarrollo sostenible de la compañía merced al gobierno corporativo ¿qué es lo más importante? ¿la estrategia? ¿la rentabilidad y el valor? ¿el papel del directorio? ¿la gerencia? ¿los controles? ¿la auditoría? ¿los clientes? ¿la sanción social?

Diría la calidad de decisiones que se toman, tomando en cuenta, no solo los aspectos financieros y económicos, sino también los aspectos medioambientales, sociales y de gobierno corporativo.

\section{¿Cuál es la importancia del directorio en el gobierno corporativo y cómo ve el rol de la gerencia general?}

Voy a leer en este tema, en esta encuesta de la "Voz de Mercado". Recibimos un comentario de un inversionista institucional, que decía, en general, todavía hay mucho espacio para mejorar el gobierno corporativo en las empresas peruanas, también hay amplio espacio para mejorar el rol de los directorios y la forma como se selecciona los directores, tanto dependientes, como independientes, el rol principal del directorio es la formulación de estrategias, para el crecimiento y generación de valor en las compañías y ello implica, que "empatizar" con la administración y con los accionistas controladores. No es necesariamente parte del mandato, más bien retar y discutir a fondo las acciones estratégicas y generar una sana discusión que permite tomar decisiones más asertivas y bien sustentadas, entonces, el directorio, viene a ser esa cabina de control, donde hay un piloto, es el gerente general y es el que está dirigiendo esta mega airbus, este avión, pero están todos los paneles de control y todas las otras cosas que hay que ver y tiene a su costado a este otro copiloto, no, que le está diciendo temas del oye mira, el tiempo, o como está el entorno, que es lo que está pasando, la gasolina como está, y que está viendo tratando de ver cada vez más adelante, tiene radar, el directorio parte de ese rol, de ayudar viendo hacia adelante.

La idea del gerente general como un mero secretario o como un mero administrador de trámites, es una idea del pasado, hoy día el gerente general bien formado, que ejerza liderazgo, como los que entiende ustedes de forman, es una persona competente, que tiene las capacidades suficientes para poder persuadir, que su manera, de ver las cosas es la adecuada para la compañía y que tiene además, la habilidad de negociar y en su caso de tolerar, cuando no le dan la razón, entonces no es que es el dueño de la verdad, es alguien que está a cargo de ser el piloto, pero que tiene coordinar, persuadir, influir y también dejarse aconsejar.

\section{Además de la información financiera ¿qué otras prácticas considera importantes para lograr la integridad corporativa? ¿De qué manera es esto visible en las organizaciones o para cualquier persona?}

Una cosa son los números que refleja que hace una empresa eso de que hace, se documenta en el estatuto social, esta empresa está dedicada a la comercialización, esta es una empresa inmobiliaria, esta es una empresa minera y dice que hace, pero cuando hablamos de integridad o de ética empresarial, en realidad de lo que estamos hablando no es del que, sino del cómo, de cómo haces ese que, que dices 
que haces y en el cómo. Pueden haber dos empresas mineras, dos empresas inmobiliarias, dos empresas constructoras o dos empresas comercializadoras y que hacen las cosas totalmente de una manera diferente, ese cómo, tiene mucho que ver con, quien soy como empresa o quienes somos en la empresa, en qué creemos y como nos vinculamos con todo nuestro grupo de interés, con nuestros trabajadores, con nuestros clientes, con las autoridades, con los vecinos, con los proveedores, con los alumnos que van a ser los futuros de repente miembros de la organización, con las familias como nos vinculamos y ahí el instrumento de gestión, que ayuda a que personas muy diversas, compartan un quienes somos, es el código de conducta, o los principios, o la filosofía corporativa, que son lineamientos o principios, o valores que ayudan, a que ese grupo de personas, pase a ser realmente un equipo con un norte común y que pueda comenzar a forjar cultura pero, no basta tenerlos en papel, hay que vivirlos entonces la integridad, ese tema del cómo somos, tiene que ver, con lo que creemos, pero también con lo que hacemos y si es que lo predicamos con el ejemplo.

Las personas observan a las principales empresas, en que lo que dicen acerca de cómo hacen las cosas e incluso sobre este tema, las empresas van un paso más allá, y tienen un propósito. Ya no es solo el qué hago, ya no es solo cómo lo hago, sino es por qué lo hago, y en ese por qué hoy día en el mundo, un líder es la compañía que marca el estándar, por ejemplo, ese porque lo hago es algo, que significa trascender, entonces por ejemplo nosotros en E\&Y nuestro propósito es "buildling a better working work" a través de los servicios que damos; servicios de auditorías, asesorías en impuestos, asesorías de negocios, etc etc. Son los qués, el cómo tiene que ver con nuestros valores y los propósitos, hacemos todo esto que estamos haciendo y las cosas que hacemos por responsabilidad social, o este esfuerzo que hacemos con la bolsa, por ejemplo, esa es una manera de contribuir a crear un mejor entorno de negocio, un mejor ecosistema y un mejor entorno para trabajar.

\section{Sobre empresas familiares ¿cuáles son los beneficios de la adopción del gobierno corporativo? ¿Qué sacrifica una organización familiar de no adoptarlo? ¿Y qué sacrificaría al adoptarlo?}

El mayor beneficio es el tema de ponerle patitas a largo plazo es decir trabajar en la sostenibilidad del negocio, que significa garantizar una rentabilidad hoy y en el mediano plazo; tener reglas claras para resolver disputas intrafamiliares y sobre todo procesos y reglas que ayuden a prevenir cualquier desavenencia. Una desavenencia entre miembros de una familia, es algo que nos llega al corazón, no, es eso básicamente, se ven los beneficios y qué perjuicio tiene, yo no sé si es perjuicio, si no qué nivel de inversión se requiere, y requiere una inversión al más alto nivel, porque es de voluntad política de quienes tienen a su cargo la empresa y que son en ese momento los patriarcas de las ramas familiares o de la familia en general, y poder ver que esto beneficia para que la empresa perdure en el tiempo. Entonces, la voluntad política, es una inversión alta, y requiere una inversión en tiempo; no solo decir oye si me comprometo y saco un correo y todos los miembros de la familia o en el WhatsApp de la familia ya lo dije esto es importante, sino ponerle tiempo y luego documentar cuales son los acuerdos eso puede ser una inversión económica menor, lo puede hacer el abogado interno, lo hace un académico lo hace un consultor, o sea hay distintas personas que podemos hacer eso, pero la inversión más importante y quizás lo más demandante es la voluntad política y el tiempo que supone si es que uno quiere ser una empresa familiar que perdure en el tiempo o una familia empresaria que perdure en el tiempo.

Uno de los grandes dramas de las empresas familiares que son la mayoría de empresas en el mundo, son pasar de la primera generación a la segunda, no solo es traspasar las acciones, no solo es ver que tenga un buen gerente, si no es como preparas a la segunda generación y eso implica de parte de la primera o en su momento de la segunda, de pensar que uno no es eterno, y este concepto de este pensamiento de la omnipotencia de la eternidad, es algo que juega en contra del emprendedor, y especialmente si es un emprendedor que se vuelve patriarca comenzar a pensar en algún día no voy a estar y tengo que prever esto, y ahí hay un tema por eso las empresas familiares estás hablando de un digito que llega a pasar a la tercera generación.

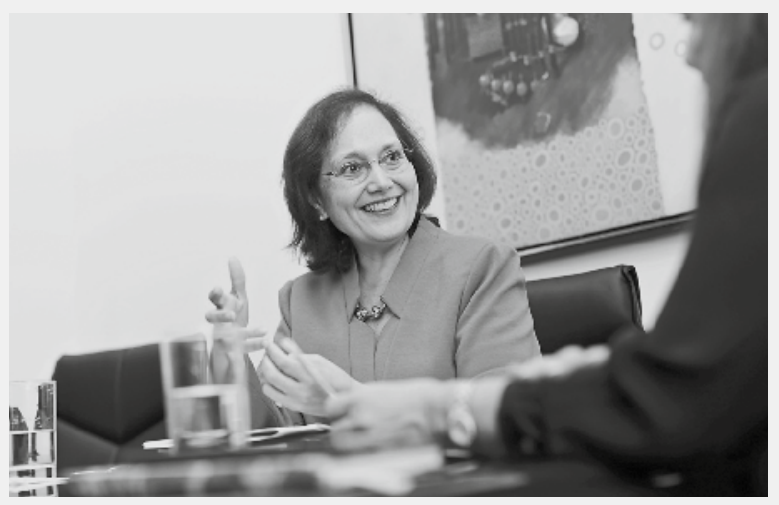

Sobre la ética profesional y ética corporativa, ¿qué revisiones importantes haría sobre el tema? ¿Cuáles serían sus propuestas?

Ponerlo en práctica. Yo diría, que lo más importante no es lo que declaro, no es lo que pongo en brochures, ni en carteles por más que aparezcan en toda la oficina lo más importante es qué es lo que la gente siente a través de mi ejemplo, qué es lo que la gente percibe a través de los vínculos que se establecen con las personas que ostentan posiciones de liderazgo en la organización, entonces poner en práctica, lo que se predica esta tan o más importante que poder predicarlo.

\section{Se han realizado algunas mejoras sobre la adopción de nuevas prácticas de Gobierno Corporativo para el año próximo, ¿recomendaría algunas adicionales? Por ejemplo para su composición?}

Si uno lo ve así no tendríamos que distinguirlo de las principales empresas que tienen más liquidez en el mercado de valores peruano el tema es calidad de información, y, en el caso del siguiente grupo de empresas, en el mercado de valores peruano, el tema es profesionalizar más la gestión y atender mejor al inversionista. El tener una oficina de atención al inversionista, en el caso de empresas familiares que 
todavía están cerradas que no cotizan en bolsa, uno de los principales desafíos es como generas un directorio que no sea el almuerzo de los domingos, sino un directorio más profesional, visado en sus procesos y en sus tomas de decisiones, si ya te encaminan en esa vía el siguiente paso es como invitas a directores independientes, dependiendo de las necesidades que tengas, de repente alguien dice oye mi debilidad ahorita es marketing, bueno hay que invitar a gente que haya estado en puestos importantes de marketing y que sean directores independientes, otros dicen es el tema digital, bueno, se consiguen personas, otro dicen es una industria regulada no sé, dependiendo en que rubro estoy, que perfil de personas pueda requerir, e invitarlas, ahí luego tienes el siguiente vas teniendo siguientes desafíos dependiendo de dónde esté la empresa, no hay una talla que sea igual para todas, depende que tipo de empresa, cuál es su situación en el mercado, qué objetivos tiene, la estrategia, hacia dónde va, para poder ver que personas necesitas y cuáles son los siguientes pasos.

Revisando las Top Form One Hundred compañías del año pasado en Estados Unidos, se nombraron como directores, en un 87\% aproximadamente, a personas que ostentaban antes el cargo antes de gerente general, gerente financiero o gerente de operaciones; entonces el conocer la operatividad en un sector, conocerlo con experiencia práctica, es un atributo valorado en el perfil de las compañías norteamericanas, un segundo perfil yo diría ese es el mayoritario

Esto nos lleva un segundo punto para la composición ideal. El tema de la composición ideal de un directorio y quizás el gran desafío que tenemos en américa latina es que en un mundo de disrupción en los negocios, en un entorno cambiante, en un mundo globalizado donde hay cada vez más incertidumbre, se requiere ampliar las perspectivas, se requiere entender cosas nueva. Jack Ma de Alibabá, decía hace un par de meses que en quince años el mundo de los negocios no se va parecer en nada a lo que es de hoy día y eso lo viene diciendo desde hace 20 años pero nadie lo oía y ahora si lo oyen, porque es Jack Ma y durante este entorno de cambios que puede ayudar a la gerencia y a la empresa, el tema de la diversidad en el directorio y, la diversidad no es un fin en sí mismo sino es un medio para permitir que el directorio tenga distintas perspectivas. Otros ángulos, esos otros ángulos pueden ser el ángulo del académico que oye todo lo que está pasando y como se ve, puede ser el ángulo de alguien que viene de otra industria work perfect en donde se habla de la necesidad de diversidad y a veces muchas de las mejores ideas no ha venido de alguien que conocía la industria, sino ha venido de alguien precisamente de otras industrias.

Puede ser de repente un artista, un filósofo, un sociólogo, pero, más allá de la diversidad de profesiones, más allá lo que importa que haya una discusión, que sea un espacio donde pueda haber una co-creación colectiva y no es un tema más marcial, o un tema más jerárquico, o un tema oye ya se dijo esto se aprueba, sino que sea un espacio donde se forme de manera colectiva la voluntad de la empresa.

\section{Dada su reconocida y larga trayectoria profesional en materia de gobernanza, ¿cuáles son para usted los errores que no deben cometerse y las lecciones aprendidas más importantes?}

Business as usual, o sea, los negocios como siempre y creer porque en el pasado fuimos exitosos, vamos a seguir siendo exitosos, creo que es uno de los errores, que no podría haber, o sea, como se dice la complacencia.

Siempre lo hemos hechos así, entonces porqué pensar en cuestionarlo y porque perder tiempo en profundizar sobre ello y esto nos lleva a una complacencia de Business as usual, creo que ahí se anidan algunos de los errores, que en términos personales tienen que ver con la falta de humildad de la cual yo peco muchas veces, la falta de humildad para reconocer que hay mucho que todavía no sabemos. Errores, sí veo los escándalos o los casos de escándalos, a nivel internacional, los casos de empresas que terminaron perdiendo valor o incidentes que ha habido en el mercado de capitales peruanos. Otro tema es no pensar, que porque estoy en un puesto de dirección y puedo tomar decisiones y tiene que ver, porque además soy el accionista, eso es todo lo que importa, hoy día hay en el mundo muchos otros grupos de interés stakeholders que entran a tallar y hay que tomarlos en cuenta.

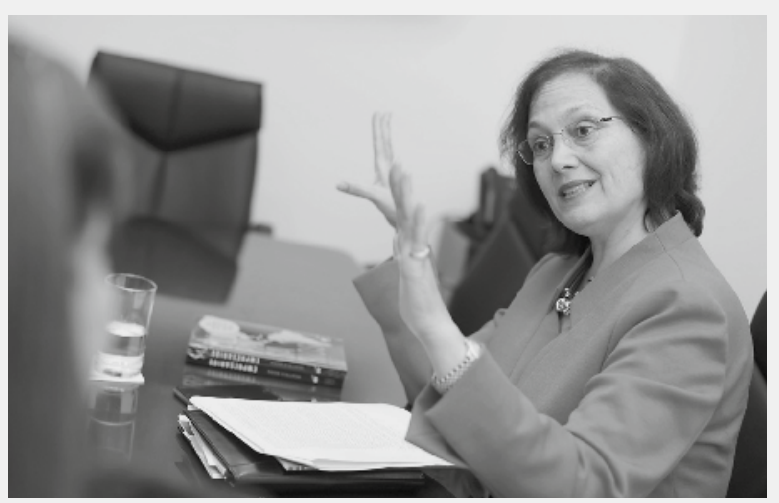

Puede haber algunos stakeholders que de repente no los tengo visualizados pero que existen o algunos que no tienen el poder y en consecuencia no están legitimados, pero no importa que alguien tenga o no el poder y que grite o no grite, lo importante es que, si como organización he incorporado todos esos factores en estrategia de negocios para ser sostenible.

Claramente, posturas como el "no ver", se relacionan con la formación, porque creo que personas de distintas religiones podemos compartir el valor de respetar la persona humana, quizás porque lo hacemos, tenemos creencias diferentes pero, valores básicos como la verdad, como la justicia, como la solidaridad, la responsabilidad, la excelencia, independientemente del credo podemos compartirlo; pero se requiere una sólida formación en el mundo de los negocios, de cómo esos valores se aterrizan en el mundo de los negocios. 
Sobre la ocurrencia de delitos, diría que de lecciones aprendidas hay varias....Y la principal es responsabilidad del directorio que la empresa cuente con las herramientas necesarias, para poder cumplir el directorio con su función de supervisión, entonces, la compañía tiene que tener una buena estrategia de negocios, que debería estar documentada, para que el directorio pueda periódicamente revisarla, la compañía debería tener un mapa de los riesgos, que no este solo la cabeza del gerente o en la cabeza del dueño, sino que este documentando y evidenciado para que el directorio de manera colectiva pueda entenderlo y monitorearlo; la compañía debería de tener una estrategia de ¿cuál es la información que se va a dar?, información sobre los productos, información que vas a tener que cumplir con las autoridades, información de distinto tipo, y también del otro lado debe estar, de esta política de información, cual es la información que debe ser reservada para la compañía, porque es parte de su know how o parte de su ventaja competitiva o sea hay herramientas y como tenemos que ver con temas de integridad, hay una herramienta que se llama el código de conducta o los principios corporativos o como se le quiera denominar, hay otra herramienta que es tener mecanismos para fomentar las denuncias anónimas y que estén protegidas; muchas veces se hacen tercerizando esos servicios. El tema de tener las instancias necesarias que van a evaluar estas denuncias, o sea, hay herramientas que son responsabilidad del directorio que estas existan, si vas a una empresa muy grande de repente las estructuras que se requieren para soportar ello son mayores y si es una empresa muy pequeña, de repente basta que en una reunión semanal se converse y se ponga en agenda, se requiere todo esto y para que se haga todo esto el directorio tiene que tener un plan de trabajo, que es lo que van a ver no de manera reactiva sino de manera proactiva entonces hay varias herramienta en una de las lecciones aprendidas de las empresas más grandes tiene que ver con la calidad de su información financiera y el rol que cumple el cometer auditoria.

\section{¿Diría usted que la ocurrencia de delitos económicos, como la malversación de activos, sobornos, corrupción, fraudes en compras y contrataciones y fraudes contables, entre otros, obedece, precisamente a la falta de gobernanza?}

En la encuesta que hemos hecho en el año 2016 con la bolsa de valores, esta encuesta se llama "La voz del mercado", 95 \% de los encuestados, declaraba que, la calidad del ambiente de control o la gestión de riesgos, son influyentes en las decisiones de inversión y habían algunos otros comentarios que decían, he visto a gerentes de portafolio, decir, no invertir, aunque la rentabilidad era importante, si es que, no había una confianza suficiente sobre la calidad del ambiente de control de la gestión de riesgos de la compañía y sin embargo la siguiente pregunta que hicimos fue ¿Considera usted que las empresas de la bolsa de valores de Lima tienen sistemas de prevención de delitos?, que es un componente de la gestión de riesgos, y solo 31\% dijo la mayoría o todas las empresas.

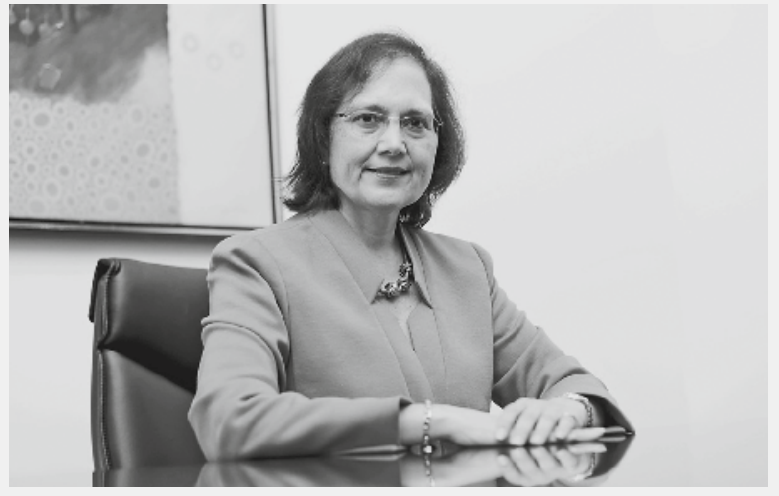

Entonces, dicen tener un buen ambiente de control, tener un buen sistema de gestión de riesgos, 95\% te dice esto influye, si es que voy a invertir contigo y cuando se pregunta oye y respecto al tema de coimas, de prevención de delitos, ¿crees que las empresas peruanas lo tienen?, solo unos de cada tres te dicen bueno, si la mayoría, ni siquiera todas, solo el $3 \%$ dijeron todos lo tienen, entonces hay una brecha importante, que es una agenda pendiente.

\section{¿Tema de estrategia, de falta de formación, de intereses?}

Quizás porque en el Perú tenemos; veamos en donde estamos, estamos cerca de Chile, cerca de Colombia, hemos sido capital de Virreinato como México, comparémonos con esos países que son de la Alianza del Pacifico ¿Cuál país de ellos es el que tiene un mayor porcentaje de la economía que es informal? Perú ¿Cuál de esos países es donde hay menos seguridad jurídica según los indicadores del banco mundial? Perú ¿Cuál de esos países es el que según transparencia internacional o según el latinobarómetro existe más probabilidad de que un conciudadano viole la ley? Perú. Vivimos en un marco institucional en que tenemos todas las leyes en el papel pero que no se cumplen. En Chile, uno respeta al carabinero, en Colombia otro país de la Alianza del Pacifico, el consejo de estado pues tiene peso, entonces, en ese entorno quizás culturalmente los peruanos estamos más acostumbrados a encontrar salidas rápidas o a no mirar, entonces es básicamente un tema cultural, en que estamos más parecidos a México, pero México es una economía pues muchísimo más grande que la nuestra, estamos más parecidos a México, pero creo que ya se ve, yo creo que esta década estamos viendo a nivel de grupos familiares de empresarios, una apuesta por la formalización, por la integridad y no solo por cumplir la ley.

Yo creo que estamos viviendo un cambio de época y si vemos y veo empresarios peruanos dando el salto, y diciendo bueno quiero hacerlo con los mejores estándares, con el mayor nivel porque estoy apostando a largo plazo, estoy, quiero crear desde hoy, un largo plazo sostenible para dejárselos a mis hijos. Apostemos por eso. 